\title{
Adnexal Dysplasia
}

National Cancer Institute

\section{Source}

National Cancer Institute. Adnexal Dysplasia. NCI Thesaurus. Code C120862.

A finding of dysplasia in the adnexal appendages. 